\title{
Reamed Intramedullary Nailing has an Adverse Effect on Bone Regeneration During the Distraction Phase in Tibial Lengthening
}

\author{
Keun Jung Ryu MD, Bang Hyun Kim MD, Jin Ho Hwang MD, PhD, \\ Hyun Woo Kim MD, PhD, Dong Hoon Lee MD, PhD
}

Received: 28 July 2015/Accepted: 21 October 2015/Published online: 27 October 2015

(C) The Association of Bone and Joint Surgeons \& 2015

\begin{abstract}
Background The lengthening over nail (LON) technique has gained popularity because it enables shorter periods of external fixation, prevents deformities during lengthening, and reduces the risk of refracture after removal of the frame compared with the classic Ilizarov method. However, it is not clear if the violation of endosteal blood supply by reamed intramedullary nailing in the LON technique has a negative effect on bone regeneration or a positive effect by compensatory enhancement of periosteal circulation.
\end{abstract}

Each author certifies that he or she, or a member of his or her immediate family, has no funding or commercial associations (eg, consultancies, stock ownership, equity interest, patent/licensing arrangements, etc) that might pose a conflict of interest in connection with the submitted article.

All ICMJE Conflict of Interest Forms for authors and Clinical Orthopaedics and Related Research ${ }^{\mathbb{R}}$ editors and board members are on file with the publication and can be viewed on request.

Clinical Orthopaedics and Related Research ${ }^{\circledR}$ neither advocates nor endorses the use of any treatment, drug, or device. Readers are encouraged to always seek additional information, including FDAapproval status, of any drug or device prior to clinical use.

Each author certifies that his or her institution approved the human protocol for this investigation, that all investigations were conducted in conformity with ethical principles of research, and that the informed consent for participation in the study was obtained. This work was performed at Severance Children's Hospital, Yonsei University College of Medicine, Seoul, Korea and CHA Bundang Medical Center, CHA University, Sungnam, Kyungki-do, Korea.

K. J. Ryu, J. H. Hwang, H. W. Kim, D. H. Lee ( $₫)$ Division of Orthopedic Surgery, Severance Children's Hospital, Yonsei University College of Medicine, Seoul 120-752, Korea e-mail: orthopaedee@naver.com; drdonghoon@yuhs.ac

B. H. Kim

Department of Orthopedic Surgery, CHA Bundang Medical Center, CHA University, Sungnam, Kyungki-do, Korea
Questions/purposes The purposes of this study were to (1) compare the amount of regenerate bone during the distraction phase between two tibial lengthening techniques, the LON technique and lengthening and then nail (LATN) technique; and (2) compare callus shape at the end of the distraction phase using the classification of $\mathrm{Li}$ et al. Methods This is a retrospective study comparing two treatment groups. Between September 2011 and June 2013, 120 patients underwent bilateral lower leg lengthening for familial short stature with either the LON or LATN technique, and were considered potentially eligible for inclusion in this retrospective, comparative study. During this same period, LON and LATN techniques were used in other patient populations, but all patients with familial short stature were considered for inclusion in the study. The specific contraindications for LON were diameter of the isthmus of the tibia narrower than $8 \mathrm{~mm}$, length of the tibia shorter than $270 \mathrm{~mm}$, and alignment of the lower extremity in valgus; in patients without these specific contraindications to LON, patients were offered either LATN or LON after counseling regarding the advantages and disadvantages of each procedure. The proposed advantages of LATN were shorter healing index and more stable internal fixation which might lead to earlier full weightbearing, whereas proposed disadvantages were a greater chance for deep infection, more deformity during lengthening, and subsequently longer external fixator period for correction. The groups were comparable in terms of age, sex distribution, smoking history, BMI, distraction rate, and final length gain. A longer period of external fixation was necessary in the LATN group, related to the relative stability of the segment without an intramedullary nail. Patients with tibial lengthening with the LON technique ( 31 patients, 62 tibiae) were compared with patients who had the LATN technique (89 patients, 178 tibiae) 
regarding the amount of bone regeneration at the anterior, posterior, medial, and lateral cortices of the lengthened area for each at 4,8 , and 12 weeks postoperatively using a pixel value ratio method. In addition, both groups were compared for callus shape and type at the end of the distraction phase (LON, $3.4 \pm 0.06$ months; LATN, $4.2 \pm$ 0.05 months).

Results The pixel value ratios of the anterior, posterior, medial, and lateral cortices in the LON and LATN groups were $0.78 \pm 0.06$ and $0.74 \pm 0.05 ; 0.82 \pm 0.08$ and $0.76 \pm$ $0.05 ; 0.75 \pm 0.06$ and $0.72 \pm 0.05$; and $0.85 \pm 0.06$ and $0.82 \pm 0.06$, respectively at 4 weeks postoperatively $(\mathrm{p}$ value $>0.500$ for all); $0.75 \pm 0.05$ and $0.77 \pm 0.04 ; 0.78 \pm$ 0.05 and $0.89 \pm 0.04 ; 0.73 \pm 0.05$ and $0.82 \pm 0.05$; and $0.78 \pm 0.06$ and $0.88 \pm 0.03$, respectively at 8 weeks postoperatively ( $\mathrm{p}$ value $<0.001$ for the posterior, medial, and lateral cortices); $0.72 \pm 0.05$ and $0.76 \pm 0.03 ; 0.75 \pm$ 0.07 and $0.89 \pm 0.03 ; 0.71 \pm 0.05$ and $0.82 \pm 0.03$; and $0.78 \pm 0.06$ and $0.91 \pm 0.03$, respectively at 12 weeks postoperatively ( $\mathrm{p}$ value $<0.001$ for the posterior, medial, and lateral cortices). A greater percentage of tibiae having the generally favored fusiform-shaped callus were seen with the LATN technique (61 of 178 segments) than with the LON technique (four of 62 segments; $p<0.001$ ). There were no tibia showing the inferior concave, lateral, or central-shaped callus with the LATN technique, whereas eight tibiae (eight of 62 segments) showed concave-shaped callus with the LON technique $(\mathrm{p}<0.001)$.

Conclusions The potentially negative effect on callus regeneration from the concomitant use of reamed intramedullary nailing during the LON technique should not be overlooked. Based on our study, LATN may be a better choice for patients willing to accept the longer period of external fixation.

Level of Evidence Level III, therapeutic study.

\section{Introduction}

Lengthening of the extremities was pioneered by Codivilla [7] and Wagner [42], but their early techniques were abandoned owing to high complication rates. Thereafter, the concept of distraction osteogenesis was established by Ilizarov [13], and several modified surgical techniques have been introduced subsequently including lengthening over nails (LON) [11, 17, 28, 29, 43], lengthening over a plate [25], lengthening and then nailing (LATN) [33], and lengthening with intramedullary lengthening devices [16, 19, 21, 27, 40]. The LON technique became popular with concomitant use of a reamed intramedullary nail during the distraction phase because it enabled a shorter external fixator period and more stable regenerate bone supported internally with the intramedullary nail compared with the classic Ilizarov method [28].

Despite these purported advantages, bone healing remains controversial with the LON technique [11, 29-31, 39, 43]. A lower healing index (number of months of treatment per $\mathrm{cm}$ of new bone regenerated) has been reported with the LON technique compared with the classic Ilizarov method [30, 31, 39], whereas no difference in healing index was reported in others [11, 29, 43]. It is still not clear if concomitant use of reamed intramedullary nailing affects callus regeneration in distraction osteogenesis. Moreover, all of these studies used the healing index of the regenerate bone as the endpoint, which cannot quantify the bone regenerate during the distraction phase. Assessment of the amount of regenerate bone with more objective and quantitative tools and its serial changes during the distraction phase to measure the effect of the timing of reamed intramedullary nailing in distraction osteogenesis have not been documented, to our knowledge.

We therefore sought to (1) compare the amount of regenerate bone during the distraction phase between two tibial lengthening techniques which are different in the procedure with or without an intramedullary nailing: the LON and the LATN; and (2) compare callus shape at the end of the distraction phase using the classification of $\mathrm{Li}$ et al. [22].

\section{Patients and Methods}

\section{Patient Selection}

This is a retrospective study comparing two treatment groups, which was approved by the institutional review board at CHA University. Each patient underwent bilateral lower leg lengthening with either the LON or LATN technique between September 2011 and June 2013. Although both techniques were used in other patient populations during this time, we chose to focus only on the familial short stature population to ensure a more homogenous group. The specific contraindications for LON were diameter of the isthmus of the tibia narrower than $8 \mathrm{~mm}$, length of the tibia shorter than $270 \mathrm{~mm}$, and alignment of the lower extremity in valgus; in patients without these specific contraindications to LON, patients were offered either LATN or LON after counseling regarding the advantages and disadvantages of each procedure. The proposed advantages of LATN were shorter healing index and more stable internal fixation which might lead to earlier full weightbearing, while proposed disadvantages were a greater chance for deep infection, more deformity during lengthening, and subsequently longer external fixator period. The groups were 
comparable in terms of age, sex distribution, smoking history, BMI, distraction rate and final length gain. The external fixator index (number of months wearing external fixation per $\mathrm{cm}$ of new bone regenerated) differed substantially between the groups (Table 1). There were no segments with severe tibial deformity, which would have mandated the use of the LATN technique. Inclusion criteria were: (1) skeletally mature patient; (2) no history of medical illness, fracture, or soft tissue compromise precluding the planned surgeries; and (3) bilateral tibiae that needed similar amounts of lengthening using the same technique (LON or LATN) in both legs. There were no exclusions based on the amount of lengthening planned. Among 123 patients (246 segments) initially included, six segments were excluded from analysis because of insufficient radiographic evaluations. No patients were lost to followup. This left 240 tibial segments in 120 patients for evaluation, which were categorized in two groups; the LON group (31 patients; 62 segments) and the LATN group (89 patients; 178 segments). Every patient had the same procedure performed on both limbs, under the same anesthetic. The mean age of the patients was $23.5 \pm 5.5$ and $22.8 \pm 5.3$ years in the LON and the LATN groups, respectively ( $\mathrm{p}$ $=0.701$; Table 1).

\section{Surgical Technique}

All surgeries were performed by the senior author (DHL). The bilateral surgical procedure was performed with the patient under the same general anesthetic using techniques described by Paley et al. [28] for the LON technique and Rozbruch et al. [33] for the LATN technique. In both techniques, an osteotomy was performed using a multiple drill-hole technique. A conventional tibial interlocking nail (EXPERT ${ }^{\mathrm{TM}}$ Tibial Nail; Synthes, West Chester, PA, USA) and the Ilizarov ring fixators (S.H. Pikar Orthotools Pvt, Pune, India) were used. A blocking screw was used to prevent excessive valgus change in the LON group when necessary. Distraction was started after 7 to 9 days of the latent period for both limbs. The latent period and distraction rate were decided on an individual basis and were identical for both limbs. After the desired length and alignment were achieved, distal interlocking screws were inserted in the LON technique, whereas reamed intramedullary nailing was performed with the LATN technique. Autologous bone marrow aspirate concentrate $(3 \mathrm{~mL})$ and plateletrich plasma $(3 \mathrm{~mL})$ were injected at the time of the initial surgery into the osteotomy site after skin closure to enhance bone healing $[20,34]$ for all patients.
Table 1. Comparison of demographic and lengthening variables between the two techniques

\begin{tabular}{|c|c|c|c|}
\hline Variables & $\begin{array}{l}\text { Lengthening } \\
\text { over nail } \\
\text { (31 patients; } \\
62 \text { segments) }\end{array}$ & $\begin{array}{l}\text { Lengthening } \\
\text { and then nailing } \\
\text { ( } 89 \text { patients; } \\
178 \text { segments) }\end{array}$ & $\mathrm{p}$ value \\
\hline \multicolumn{4}{|l|}{ Demographics } \\
\hline Age (years) & $23.5 \pm 5.5$ & $22.8 \pm 5.3$ & 0.701 \\
\hline Sex (male:female) & $40: 22$ & $120: 58$ & 0.793 \\
\hline $\begin{array}{l}\text { Smoking history } \\
\text { (yes:no) }\end{array}$ & $18: 44$ & $66: 112$ & 0.913 \\
\hline BMI $\left(\mathrm{kg} / \mathrm{cm}^{2}\right)$ & $21.2 \pm 2.0$ & $22.2 \pm 3.0$ & 0.326 \\
\hline $\begin{array}{l}\text { Duration of } \\
\text { followup (months) }\end{array}$ & $37.4 \pm 12.9$ & $41.7 \pm 12.7$ & 0.196 \\
\hline \multicolumn{4}{|l|}{ Lengthening } \\
\hline $\begin{array}{l}\text { Distraction rate } \\
(\mathrm{mm} / \text { day })\end{array}$ & $0.82 \pm 0.08$ & $0.88 \pm 0.09$ & 0.091 \\
\hline $\begin{array}{l}\text { Final length } \\
\text { gain }(\mathrm{mm})\end{array}$ & $64.5 \pm 7.1$ & $66.4 \pm 5.7$ & 0.322 \\
\hline $\begin{array}{l}\text { External fixator } \\
\text { index (months } / \mathrm{cm})\end{array}$ & $0.52 \pm 0.08$ & $9.63 \pm 0.08$ & 0.025 \\
\hline
\end{tabular}

Values are expressed with mean with a SD or as a ratio.

Followup and Postoperative Rehabilitation

The target distraction rate was $1 \mathrm{~mm}$ per day, but case-dependent adjustments were made by the surgeon based on clinical and radiographic followups. Among the 178 segments of lengthening with LATN, 170 had deformities develop during the distraction phase (mostly valgus and/or procurvatum deformities). One hundred twenty-two segments were corrected using the Hexapod ${ }^{\circledR}$ (Litos/GmbH \& Co KG, Rudorffweg, Germany; S.H. Pikar Orthotools Pvt) and 48 were corrected using the Ortho-SUV ${ }^{\circledR}$ (Ortho-SUV Ltd, St Petersburg, Russia), a software assisted six-pod frame. From the first postoperative day, all patients were encouraged to do daily ROM exercises of the knees and ankles, especially ankle dorsiflexion and knee extension, under the guidance of a registered physical therapist (JHP). All patients were allowed full weightbearing as tolerated while the external fixator was applied, and after the external fixator was removed, full weightbearing was allowed only when radiographic evidence of healing at two cortical surfaces was seen. Patients were followed every 2 weeks during the distraction phase and monthly during the consolidation phase. The duration of followup was $37 \pm 13$ and $42 \pm 13$ months in the LON and the LATN groups, respectively $(\mathrm{p}=0.196)$.

\section{Radiographic Evaluations}

The evaluation of callus formation was performed in two ways. First, a pixel value ratio was calculated, defined as 


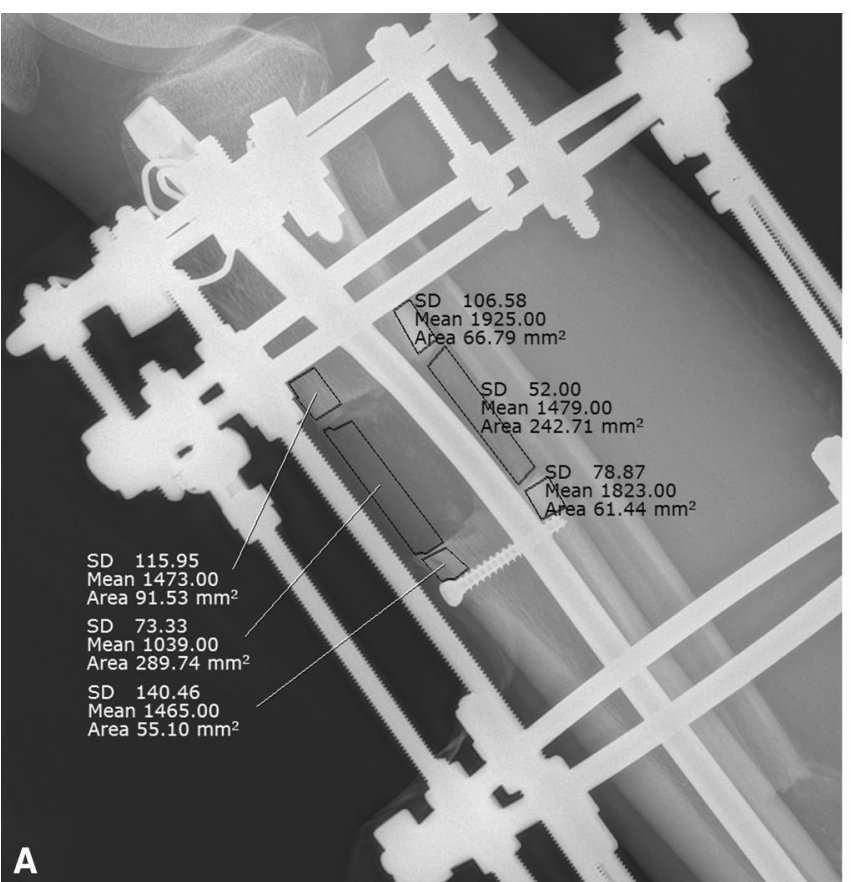

Fig. 1A-B (A) A pixel value ratio was calculated during the distraction phase in the LON technique. After a region of interest was made with a polygonal shape in the regenerate bone and the adjacent bones, the pixel value ratio was calculated. Care was taken to avoid any hardware shadows. Pixel value ratio $=($ pixel value of the regenerate bone $) /([$ pixel value of the proximal adjacent bone + pixel value of the distal adjacent bone]/2); Mean = mean pixel value of the

the ratio of pixel value of the regenerate bone versus the mean pixel value of the proximal and distal adjacent bones of the lengthened area on radiographs [38] (Fig. 1). It can be measured using tools in the PACS system (STAR PACS Pi view, STAR 5.06.1 software; INFINITT, Seoul, South Korea). Pixel value ratio at the anterior and posterior cortices can be measured from the lateral radiograph and pixel value ratio at the medial and lateral cortices can be measured from the AP radiograph. The ratio was calculated at three times postoperatively $(4,8$, and 12 weeks) for each of the four cortices during the distraction phase and compared between the LON and LATN techniques at each given time postoperatively for each cortex (Fig. 2). Only selected cortical areas were analyzed as a region of interest to calculate pixel value ratio with the LON technique to avoid hardware shadows, such as the intramedullary nail. The same principles then were applied to the LATN technique to compare them in a similar fashion. Any hardware shadows including the intramedullary nail, screws, or external fixators were not included in the measurement area. Second, callus shapes were compared between the two groups at the end of the distraction phase (LON, $3.4 \pm$ 0.06 months; LATN, $4.2 \pm 0.05$ months) according to the classification of $\mathrm{Li}$ et al. [22], in which the callus is classified as fusiform, cylindrical, concave, or lateral; generally

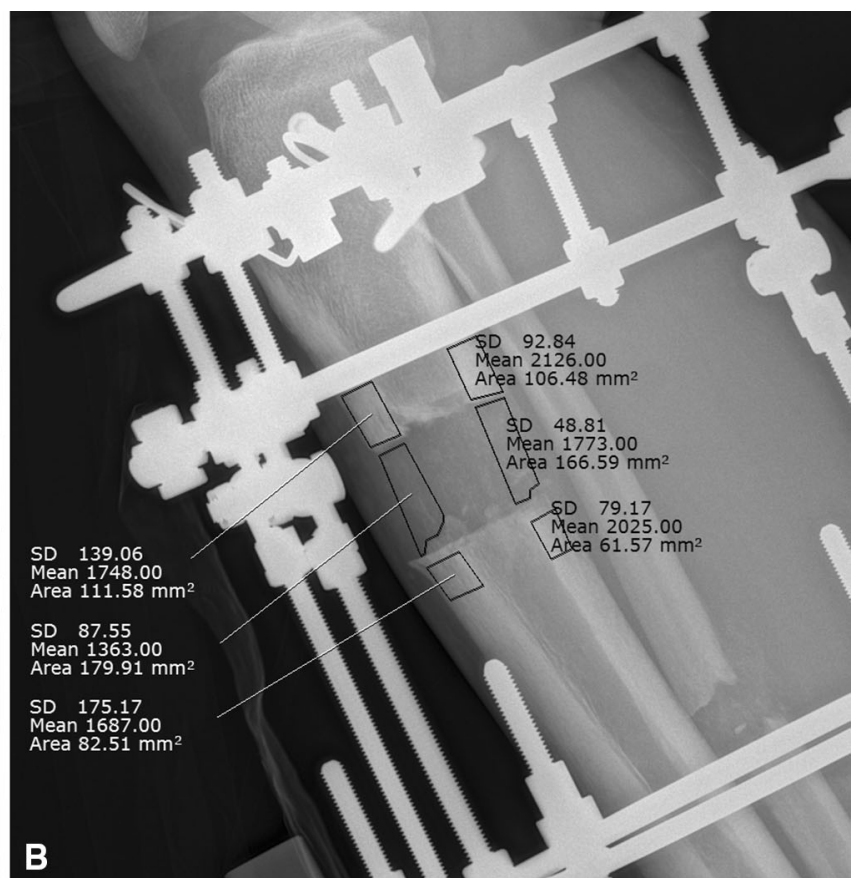

region of interest; $\mathrm{SD}=\mathrm{SD}$ of the pixel value of the region of interest; Area $=$ area of the region of interest. $($ B) A pixel value ratio was calculated during the distraction phase in the LATN technique. After a region of interest was made with a polygonal shape in the regenerate bone and adjacent bones, the pixel value ratio was calculated. Care was taken to avoid any hardware shadows. $\mathrm{LON}=$ lengthening over nail; LATN = lengthening and then nailing.

the fusiform shape is thought to be superior regenerate bone compared with the concave shape. These radiographic parameters were assessed by two of the authors (BHK, $\mathrm{JHH}$ ) not involved in the surgery, with good interrater agreement in pixel value ratio (interclass correlation, $0.81-$ 0.91 ) and almost perfect interrater agreement in callus shape (kappa, 0.97-0.99).

\section{Statistics and Sample Size Calculation}

All continuous variables including pixel value ratio and demographic data were expressed as mean with SD and tested for normality using the Shapiro-Wilk test, which allowed normal distribution assumption. At the beginning of the study, an a priori power analysis was conducted for detection of differences of pixel value ratio between the two groups, with a statistical significance of 0.05 . The calculated effect size was 0.6 based on the power analysis with given value of significance level and power, 0.05 and 0.8 respectively, so that the difference between the two groups can have high reliability with the effect size. The fixed value of power 0.8 suggested that 45 patients were needed for each group, which was exceeded in our study. Demographic and lengthening variables were compared 

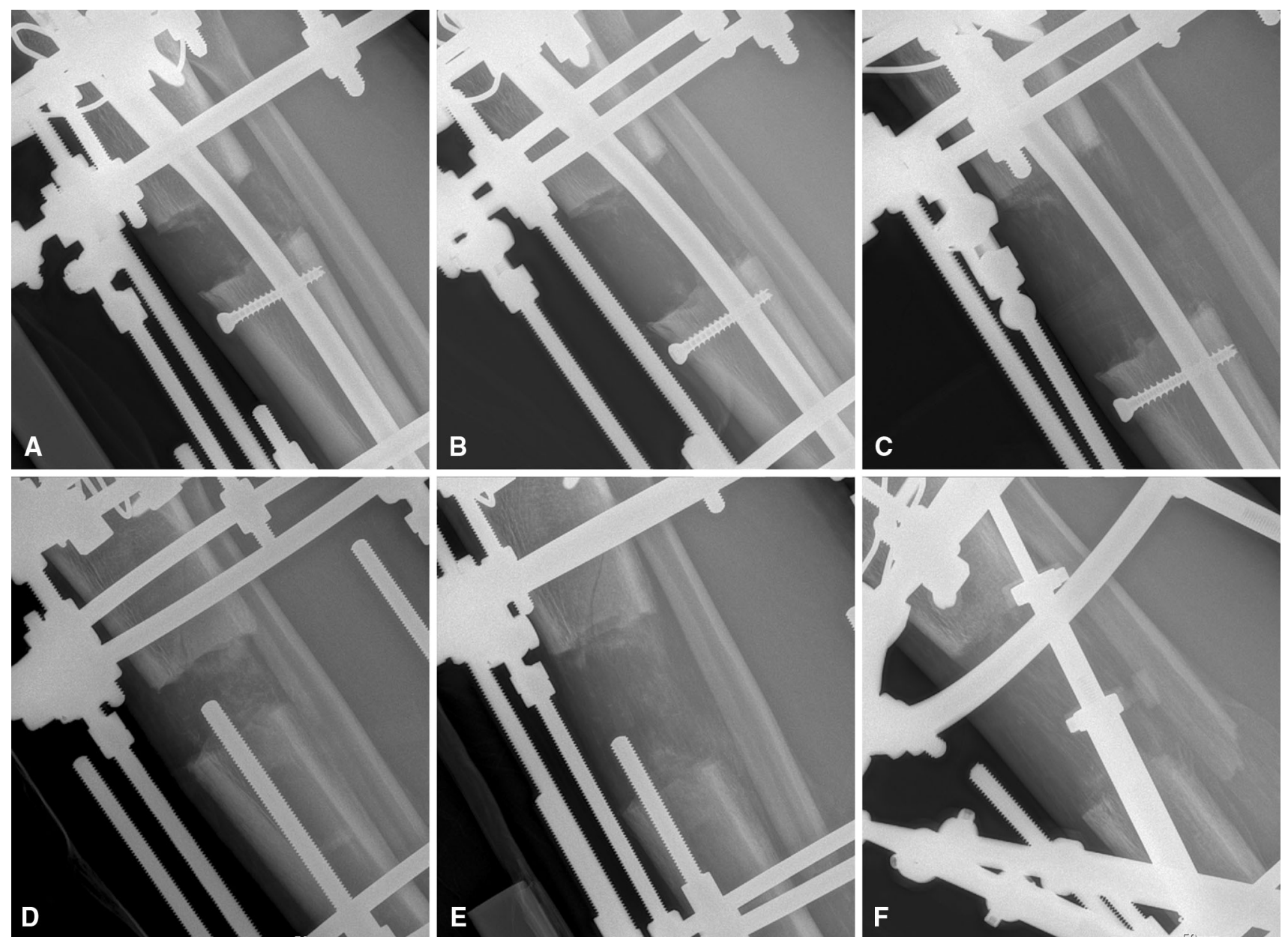

Fig. 2A-F Serial lateral plain radiographs show a tibia undergoing lengthening. Radiographs were taken at (A) 4, (B) 8, and (C) 12 weeks postoperatively in the LON group, and (D) 4, (E) 8, and (F) 12

between the two groups using Student's t-test. The pixel value ratio obtained at each time postoperatively for each cortex also was compared between the two groups using Student's t-test. Categorical variables, including callus shape at 2 years postoperatively, were summarized and compared between the two groups using a chi-square test. Probability values less than 0.05 were considered statistically significant throughout. The statistical software MedCalc (Version 11.6; MedCalc Software, Mariakerke, Belgium) and R (Version 3.1.0; Comprehensive R Archive Network, GNU General Public License, Boston, MA, USA) were used for all statistical analyses.

\section{Results}

Pixel value ratio of anterior, posterior, medial, and lateral cortices in the LON and LATN groups (Table 2) were 0.78 \pm 0.06 and $0.74 \pm 0.05 ; 0.82 \pm 0.08$ and $0.76 \pm 0.05 ; 0.75$ \pm 0.06 and $0.72 \pm 0.05$; and $0.75 \pm 0.05$ and $0.82 \pm 0.06$, weeks postoperatively in the LATN group. More callus regeneration is seen in the LATN group.

respectively at 4 weeks postoperatively ( $\mathrm{p}$ value $>0.500$ for all); $0.75 \pm 0.05$ and $0.77 \pm 0.04 ; 0.78 \pm 0.05$ and $0.89 \pm$ $0.04 ; 0.73 \pm 0.05$ and $0.82 \pm 0.05 ;$ and $0.78 \pm 0.06$ and 0.88 \pm 0.03 , respectively at 8 weeks postoperatively ( $\mathrm{p}$ value $<$ 0.001 for posterior, medial, and lateral cortices); and $0.72 \pm$ 0.05 and $0.76 \pm 0.03 ; 0.75 \pm 0.07$ and $0.89 \pm 0.03 ; 0.71$ \pm 0.05 and $0.82 \pm 0.03$; and $0.78 \pm 0.06$ and $0.91 \pm 0.03$, respectively at 12 weeks postoperatively ( $\mathrm{p}$ value $<0.001$ for posterior, medial, and lateral cortices) (Fig. 3).

A greater percentage of tibiae having fusiform-shaped callus was seen with the LATN technique (61 of 178 tibiae [34\%]) than with the LON technique (four of 62 tibiae [6\%]; $\mathrm{p}<0.001$ ) (Table 3). In addition, there were no tibiae showing concave, lateral, or central-shaped callus with the LATN technique, whereas eight tibiae (eight of 62 [13\%]) showed concave-shaped callus with the LON technique (Table 3).

The distraction rate was $0.82 \pm 0.08$ and $0.88 \pm 0.09$ $\mathrm{mm} /$ day in the LON and LATN groups, respectively $(\mathrm{p}=$ $0.091)$. The final length gain was $64.5 \pm 7.1 \mathrm{~mm}$ and 66.4 
Table 2. Comparison of pixel value ratios between the two techniques

\begin{tabular}{|c|c|c|c|}
\hline \multirow[t]{2}{*}{ Cortex } & \multicolumn{2}{|l|}{ Pixel value ratio } & \multirow[t]{2}{*}{$\mathrm{p}$ value } \\
\hline & $\begin{array}{l}\text { Lengthening } \\
\text { over nail } \\
\text { (n=62 tibiae) }\end{array}$ & $\begin{array}{l}\text { Lengthening } \\
\text { and then nailing } \\
\text { ( } \mathrm{n}=178 \text { tibiae) }\end{array}$ & \\
\hline \multicolumn{4}{|l|}{ Anterior } \\
\hline 4 weeks & $0.78 \pm 0.06$ & $0.74 \pm 0.05$ & 0.605 \\
\hline 8 weeks & $0.75 \pm 0.05$ & $0.77 \pm 0.04$ & 0.525 \\
\hline 12 weeks & $0.72 \pm 0.05$ & $0.76 \pm 0.03$ & 0.326 \\
\hline \multicolumn{4}{|l|}{ Posterior } \\
\hline 4 weeks & $0.82 \pm 0.08$ & $0.76 \pm 0.05$ & 0.607 \\
\hline 8 weeks & $0.78 \pm 0.05$ & $0.89 \pm 0.04$ & $<0.001$ \\
\hline 12 weeks & $0.75 \pm 0.07$ & $0.89 \pm 0.03$ & $<0.001$ \\
\hline \multicolumn{4}{|l|}{ Medial } \\
\hline 4 weeks & $0.75 \pm 0.06$ & $0.72 \pm 0.05$ & 0.543 \\
\hline 8 weeks & $0.73 \pm 0.05$ & $0.82 \pm 0.05$ & $<0.001$ \\
\hline 12 weeks & $0.71 \pm 0.05$ & $0.82 \pm 0.03$ & $<0.001$ \\
\hline \multicolumn{4}{|l|}{ Lateral } \\
\hline 4 weeks & $0.85 \pm 0.06$ & $0.82 \pm 0.06$ & 0.814 \\
\hline 8 weeks & $0.78 \pm 0.06$ & $0.88 \pm 0.03$ & $<0.001$ \\
\hline 12 weeks & $0.78 \pm 0.06$ & $0.91 \pm 0.03$ & $<0.001$ \\
\hline
\end{tabular}

Pixel value ratio $=$ the ratio of pixel value of the regenerate bone versus the mean pixel value of the proximal and distal adjacent bones of the lengthened area on radiographs (values are mean $\pm \mathrm{SD}$ ).

$\pm 5.7 \mathrm{~mm}$ in the LON and the LATN groups, respectively $(\mathrm{p}=0.322)($ Table 1$)$.

\section{Discussion}

A lower healing index was reported in some studies with the LON technique compared with the classic Ilizarov method $[28,29]$, whereas no differences were found in others [11, 29, $39,43]$. These studies all used the healing index of the regenerate bone as the endpoint, which cannot quantify the bone regenerate during the distraction phase. It is still not clear if concomitant use of reamed intramedullary nailing affects callus regeneration in distraction osteogenesis. We compared the amount of new bone formation during the distraction phase between two surgical techniques: the LON and the LATN techniques. Because concomitant use of reamed intramedullary nails during the distraction phase with the LON technique is different from the LATN technique, we believe comparing the amount of bone regenerate during the distraction phase between the two cohorts will help in evaluating the effect of reamed intramedullary nailing on bone healing during the distraction phase.

Several limitations should be mentioned. First, the accuracy and reliability of the pixel value ratio is not fully established as an objective tool for measuring bone regeneration. Several objective diagnostic tools for assessment of regenerate bone have been introduced such as dual x-ray absorptiometry [10, 23], CT [32, 35], and pixel value ratio $[12,24,38,45]$. Serial evaluation of callus during the distraction phase in leg lengthening using dual $\mathrm{x}$-ray absorptiometry or CT is limited because of repeated radiation exposure and metal interference. The pixel value ratio has no such disadvantages. Zhao et al. [45] reported that a pixel value ratio can be an objective parameter for callus measurement and may provide guidelines for timing of external fixator removal. Hazra et al. [12] reported that good correlation was observed between bone mineral density measured with dual $\mathrm{x}$-ray absorptiometry and pixel value ratio with a Pearson's coefficient of correlation of 0.79 . Song et al. [38] reported that serial measurement of the pixel value ratio is a reliable and cost-effective method to assess the maturity of the callus in tibial lengthening without nailing. Second, hardware, fibular shadows, or small bone pieces or debris adjacent to the osteotomy site could bias the measurement of pixel value. These do not represent true bone regeneration, and therefore should not be included in the region of interest in the picture archive and communication system when calculating the pixel value. In addition, measurement of pixel values depends on how the region of interest is subjectively constructed in the picture archive and communication system. However, we attempted to exclude these extraneous shadows when drawing a region of interest. Third, the groups were not randomized. Even though there was no statistical difference in demographics between the groups, untoward selection bias factors (eg, we chose the LATN method when the length or the diameter of the tibia was too short or narrow) might have influenced the results. The following factors also could have affected the results in undetermined ways: the surgeon (DHL) (who knew the treatment method used) had independent control over the rate of lengthening and deformities in the patients who had the LATN technique which required correction with the Hexapod $^{\mathbb{R}}$ or Ortho-SUV ${ }^{\mathbb{R}}$ that did not occur in the patients who had the LON technique. Finally, drawing a region of interest for calculation of pixel values ratio and evaluation for final callus shape could not be blinded because the radiographs reveal which technique was used, which potentially could bias the overall study results.

In our study, greater pixel value ratios were observed in patients treated with the LATN technique than in patients treated with the LON technique at 8 and 12 weeks postoperatively at the posterior, medial, and lateral cortices. In addition, the pixel value ratio showed a continuous decreasing trend during the 12 -week period during the distraction phase in the LON technique in contrast to the LATN technique (Table 2; Fig. 3). We believe this may be explained by enlarging areas of interest used for calculating 


\section{Anterior Cortex}

pixel value ratio

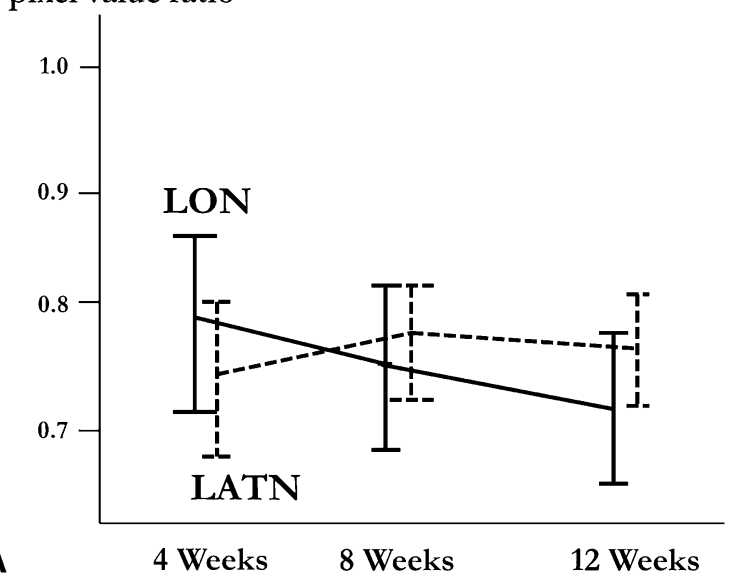

A

Medial Cortex

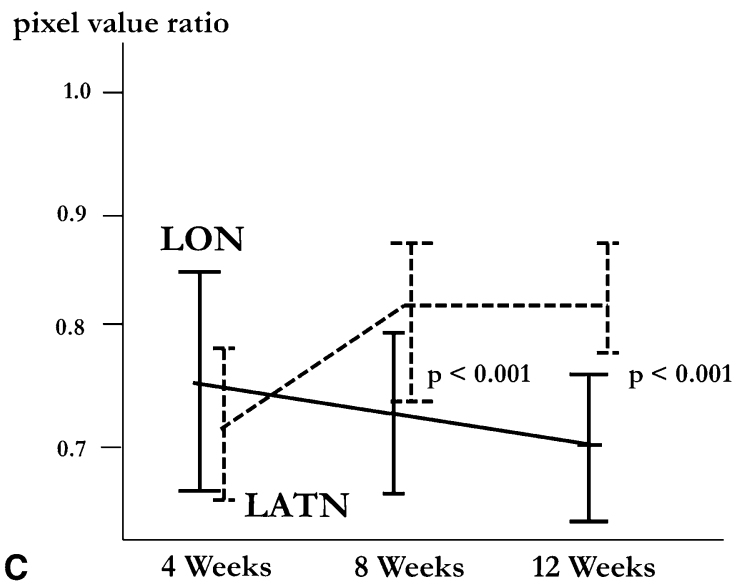

Fig. 3A-D Serial bar plots with the mean and 95\% CI of the pixel value ratio of the anterior cortex at three times with two different surgical techniques are shown for the $(\mathbf{A})$ anterior, $(\mathbf{B})$ posterior, $(\mathbf{C})$ medial, and (D) lateral cortices. The pixel value ratio showed no significant differences at each time for the anterior cortex. For the

pixel values as the distraction progressed and failure of the density of regenerate bone to "catch up with it" in the LON technique. This theory would support more regenerate bone with the LATN technique, which showed a continuous increasing trend or a plateau of the pixel value ratio. Finally, the pixel value ratio at the anterior cortex showed no differences between the two techniques throughout the study period, with relatively low pixel value ratios throughout. This might be explained by the incision placement for the tibial osteotomy, relatively poor soft tissue coverage over the anterior tibia compromising blood flow to this region, or biomechanical aspects of force transmission during weightbearing.

Reamed intramedullary nailing has become the mainstream treatment of long-bone diaphyseal and selected

\section{Posterior Cortex}

pixel value ratio

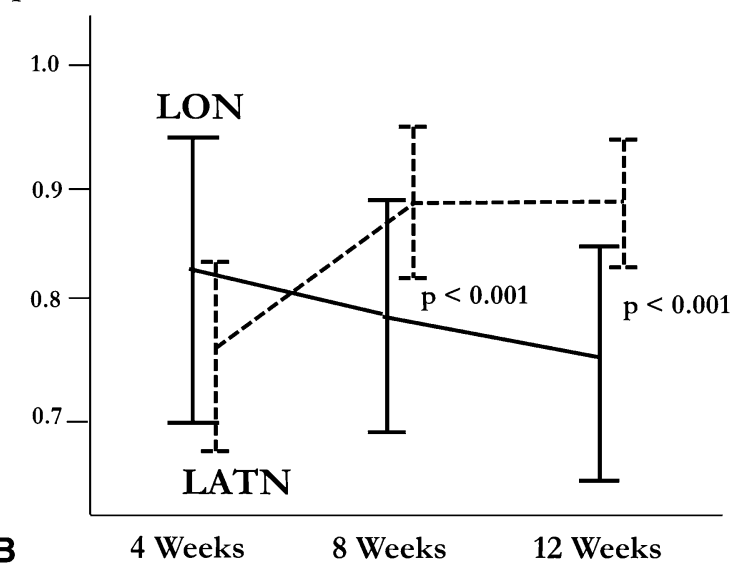

\section{Lateral Cortex}

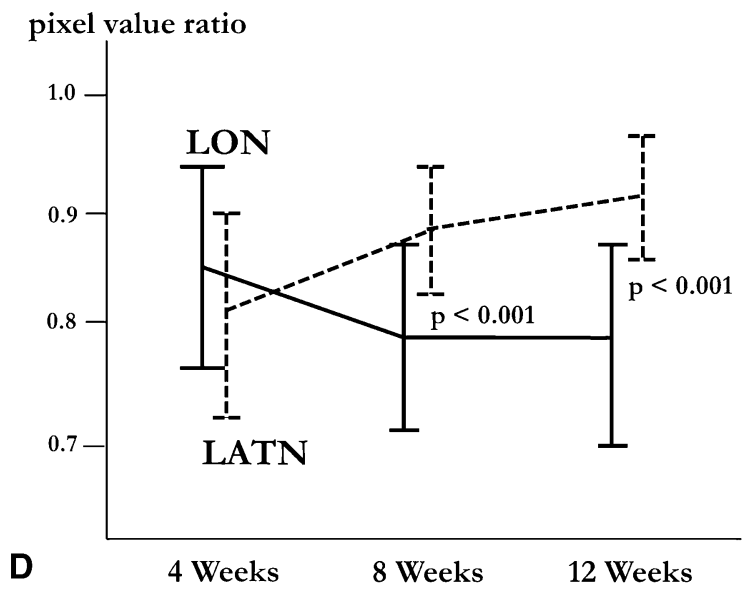

posterior, medial, and lateral cortices, the pixel value ratios showed significant differences at 8 and 12 weeks postoperatively, with better healing in the LATN group. LON = lengthening over nail; LATN = lengthening then nailing.

metaphyseal fractures [3, 5]. Although reaming of the medullary canal is known to have early deleterious effects on endosteal and cortical blood flow [3], it appears to have several positive effects on bone healing with various biologic mechanisms suggested, such as compensatory increase of periosteal circulation [8], local bone graft effect of reamed debris with osteoinductivity [4, 15, 41], and activation of growth factors and inflammatory responses helpful for fracture healing [2, 4, 37]. However, the effect of medullary reaming on bone regeneration in distraction osteogenesis is not fully established. Kojimoto et al. [18] reported that preservation of periosteum in a rabbit model had a profound effect in callus distraction, whereas preserving the endosteum did not by scraping periosteum and endosteum selectively. However, the scraping was done for 
Table 3. Comparison of callus shapes between the two techniques

\begin{tabular}{llll}
\hline $\begin{array}{l}\text { Callus } \\
\text { shape }\end{array}$ & $\begin{array}{l}\text { Number of tibia } \\
\text { nengthening over } \\
\text { nail }(\mathrm{n}=62 \text { tibiae })\end{array}$ & $\begin{array}{l}\text { Lengthening and } \\
\text { then nailing } \\
(\mathrm{n}=178 \text { tibiae })\end{array}$ & \\
\hline Fusiform & $4(6 \%)$ & $61(34 \%)$ & $<0.001$ \\
Cylindrical & $50(81 \%)$ & $117(66 \%)$ & $<0.001$ \\
Concave & $8(13 \%)$ & $0(0 \%)$ & $<0.001$ \\
Lateral & $0(0 \%)$ & $0(0 \%)$ & 0.999 \\
Central & $0(0 \%)$ & $0(0 \%)$ & 0.999
\end{tabular}

Callus shape was based on the classification by Li et al. [22].

only a limited area around the osteotomy, and this is a different situation from reaming the intramedullary canal in our human cohort with the LON technique. There is substantial evidence supporting the importance of vascularity in distraction osteogenesis [1, 6, 26]. Aronson [1] reported that blood flow in the lengthened limb is 10 times greater than in the control limbs at 2 weeks after lengthening, and four to five times greater for the remainder of the distraction period. Choi et al. [6] reported that osteogenic tissue filled the distraction gap in accordance with reconstitution of the periosteal vascular network followed by interconnection of the medullary circulation. Numerous clinical studies have compared the healing index with the LON technique and the classic Ilizarov method [11, 29-31, 39, 43]. Several [11, 27, 43] reported a similar healing index, whereas the others [30,31, 39] reported a lower healing index with the LON technique. In the current study, greater pixel value ratio during the distraction phase was observed with the LATN technique (surgically identical to the classic method during lengthening) when compared with the LON technique, which suggests better callus regenerate with the LATN technique.

We observed more fusiform-shaped callus with the LATN technique (61 of 178 [34\%]) than with the LON technique (four of $62[6 \%]$ ). In addition, concave, lateral, or central-shaped callus was not observed with the LATN technique, whereas concave-shaped callus was observed in eight tibiae $(13 \%)$ with the LON technique. Few studies have reported on regenerate callus shape [9, 14, 36, 39, 44] in the field of distraction osteogenesis. There has been one study [39] comparing callus shape between two limb lengthening techniques, in which the authors observed a greater incidence of fusiform-shaped callus with the classic Ilizarov method compared with the LON technique.

Our findings also support poorer formation of healthy bone regenerate with the LON technique. This may be attributed to the negative effect of reamed intramedullary nailing on bone healing during the distraction phase, but we cannot rule out the influence of other factors as mentioned in our limitations. Regarding better bone formation with the LATN technique, we agree with Rozbruch et al. [33] that reamed intramedullary nailing after completion of lengthening may have a positive effect on bone healing by autologous bone graft from reaming debris or compensatory enhancement of periosteal circulation. However, we observed that avoiding reaming during the distraction phase leads to more robust bone regenerate in lengthening of the tibia. Perhaps the presumed preservation of endosteal circulation during distraction represents another possible explanation for this effect. More comparative studies are required to verify the effect of reamed intramedullary nailing before and after lengthening in distraction osteogenesis. We believe that the theoretical preservation of endosteal circulation has a more positive effect on callus regeneration than the possible compensatory increase of periosteal circulation or local bone graft effect from the reamed particles in the setting of distraction osteogenesis.

Reamed intramedullary nailing has an adverse effect on bone regeneration during the distraction phase in distraction osteogenesis of the tibia. The negative effect that may be attributable to the concomitant use of reamed intramedullary nailing during the LON technique should not be overlooked. However, larger sample-size studies with more refined objective tools for measuring the amount of bone regeneration are required.

Acknowledgments We thank Hyun Tae Kyung MAS (College of Commerce and Economics, Yonsei University, Seoul, South Korea) for his valuable comments for the statistical analysis, and Jung Ho Park PT (Department of Rehabilitation, CHA Bundang Medical Center, CHA University) for his enthusiastic work for all our patients.

\section{References}

1. Aronson J. Temporal and spatial increases in blood flow during distraction osteogenesis. Clin Orthop Relat Res. 1994;301:124131.

2. Bhandari M, Schemitsch EH. Bone formation following intramedullary femoral reaming is decreased by indomethacin and antibodies to insulin-like growth factors. J Orthop Trauma. 2002;16:717-722.

3. Bong MR, Kummer FJ, Koval KJ, Egol KA. Intramedullary nailing of the lower extremity: biomechanics and biology. $J \mathrm{Am}$ Acad Orthop Surg. 2007;15:97-106.

4. Brinker MR, O'Connor DP. Exchange nailing of ununited fractures. J Bone Joint Surg Am. 2007;89:177-188.

5. Chapman MW. The effect of reamed and nonreamed intramedullary nailing on fracture healing. Clin Orthop Relat Res. 1998;355(suppl):S230-238.

6. Choi IH, Ahn JH, Chung CY, Cho TJ. Vascular proliferation and blood supply during distraction osteogenesis: a scanning electron microscopic observation. J Orthop Res. 2000;18:698-705.

7. Codivilla A. On the means of lengthening, in the lower limbs, the muscles and tissues which are shortened through deformity. Am J Orthop Surg. 1905;22:353-369.

8. Danckwardt-Lillieström G. Reaming of the medullary cavity and its effect on diaphyseal bone: a fluorochromic, microangiographic 
and histologic study on the rabbit tibia and dog femur. Acta Orthop Scand Suppl. 1969;128:1-153.

9. Devmurari KN, Song HR, Modi HN, Venkatesh KP, Ju KS, Song $\mathrm{SH}$. Callus features of regenerate fracture cases in femoral lengthening in achondroplasia. Skeletal Radiol. 2010;39:897903 .

10. Eyres KS, Bell MJ, Kanis JA. New bone formation during leg lengthening: evaluated by dual energy X-ray absorptiometry. $J$ Bone Joint Surg Br. 1993;75:96-106.

11. Guo Q, Zhang T, Zheng Y, Feng S, Ma X, Zhao F. Tibial lengthening over an intramedullary nail in patients with short stature or leg-length discrepancy: a comparative study. Int Orthop. 2012;36:179-184.

12. Hazra S, Song HR, Biswal S, Lee SH, Lee SH, Jang KM, Modi HN. Quantitative assessment of mineralization in distraction osteogenesis. Skeletal Radiol. 2008;37:843-847.

13. Ilizarov GA. Clinical application of the tension-stress effect for limb lengthening. Clin Orthop Relat Res. 1990;250:8-26.

14. Isaac D, Fernandez H, Song HR, Kim TY, Shyam AK, Lee SH, Lee JC. Callus patterns in femur lengthening using a monolateral external fixator. Skeletal Radiol. 2008;37:329-334.

15. Kessler SB, Hallfeldt KK, Perren SM, Schweiberer L. The effects of reaming and intramedullary nailing on fracture healing. Clin Orthop Relat Res. 1986;212:18-25.

16. Kirane YM, Fragomen AT, Rozbruch SR. Precision of the PRECICE internal bone lengthening nail. Clin Orthop Relat Res. 2014;472:3869-3878.

17. Kocaoglu M, Eralp L, Kilicoglu O, Burc H, Cakmak M. Complications encountered during lengthening over an intramedullary nail. J Bone Joint Surg Am. 2004;86:2406-2411.

18. Kojimoto H, Yasui N, Goto T, Matsuda S, Shimomura Y. Bone lengthening in rabbits by callus distraction: the role of periosteum and endosteum. J Bone Joint Surg Br. 1988;70:543-549.

19. Küçükkaya M, Karakoyun Ö, Sökücü S, Soydan R. Femoral lengthening and deformity correction using the Fitbone motorized lengthening nail. J Orthop Sci. 2015;20:149-154.

20. Lee DH, Ryu KJ, Kim JW, Kang KC, Choi YR. Bone marrow aspirate concentrate and platelet-rich plasma enhanced bone healing in distraction osteogenesis of the tibia. Clin Orthop Relat Res. 2014;472:3789-3797.

21. Lee DH, Ryu KJ, Song HR, Han SH. Complications of the Intramedullary Skeletal Kinetic Distractor (ISKD) in distraction osteogenesis. Clin Orthop Relat Res. 2014;472:3852-3859.

22. Li R, Saleh M, Yang L, Coulton L. Radiographic classification of osteogenesis during bone distraction. J Orthop Res. 2006;24:339347.

23. Monsell F, Hughes AW, Turner J, Bellemore MC, Bilston L. Can the material properties of regenerate bone be predicted with noninvasive methods of assessment? Exploring the correlation between dual X-ray absorptiometry and compression testing to failure in an animal model of distraction osteogenesis. Strategies Trauma Limb Reconstr. 2014;9:45-51.

24. Muzaffar N, Hafeez A, Modi H, Song HR. Callus patterns in femoral lengthening over an intramedullary nail. J Orthop Res. 2011;29:1106-1113.

25. Oh CW, Baek SG, Kim JW, Kim JW. Tibial lengthening with a submuscular plate in adolescents. J Orthop Sci. 2015;20:101109.

26. Ohashi S, Ohnishi I, Kageyama T, Fukuda S, Tsuchiya A, Imai K, Matsuyama J, Nakamura K. Effect of vascularity on canine distracted tibial callus consolidation. Clin Orthop Relat Res. 2005;438:253-259.

27. Paley D. PRECICE intramedullary limb lengthening system. Expert Rev Med Devices. 2015;12:231-249.

28. Paley D, Herzenberg JE, Paremain G, Bhave A. Femoral lengthening over an intramedullary nail: a matched-case comparison with Ilizarov femoral lengthening. J Bone Joint Surg Am.1997;79:1464-1480.

29. Park HW, Yang KH, Lee KS, Joo SY, Kwak YH, Kim HW. Tibial lengthening over an intramedullary nail with use of the Ilizarov external fixator for idiopathic short stature. J Bone Joint Surg Am. 2008;90:1970-1978.

30. Popkov DA, Popkov AV, Haumont T, Journeau P, Lascombes P. Flexible intramedullary nail use in limb lengthening. J Pediatr Orthop. 2010;30:910-918.

31. Popkov DA, Popkov AV, Kononovich NA, Barbier D, Ceroni D, Journeau P, Lascombes P. Experimental study of progressive tibial lengthening in dogs using the Ilizarov technique: comparison with and without associated intramedullary K-wires. Orthop Traumatol Surg Res. 2014;100:809-814.

32. Romanowski CA, Underwood AC, Sprigg A. Reduction of radiation doses in leg lengthening procedures by means of audit and computed tomography scanogram techniques. $\mathrm{Br} J$ Radiol. 1994;67:1103-1107.

33. Rozbruch SR, Kleinman D, Fragomen AT, Ilizarov S. Limb lengthening and then insertion of an intramedullary nail: a casematched comparison. Clin Orthop Relat Res. 2008;466:29232932.

34. Sabharwal S. Enhancement of bone formation during distraction osteogenesis: pediatric applications. J Am Acad Orthop Surg. 2011;19:101-111.

35. Salmas MG, Nikiforidis G, Sakellaropoulos G, Kosti P, Lambiris E. Estimation of artifacts induced by the Ilizarov device in quantitative computed tomographic analysis of tibiae. Injury. 1998;29:711-716

36. Schemitsch EH, Turchin DC, Kowalski MJ, Swiontkowski MF. Quantitative assessment of bone injury and repair after reamed and unreamed locked intramedullary nailing. $J$ Trauma. 1998;45:250-255.

37. Smith RM, Giannoudis PV, Bellamy MC, Perry SL, Dickson RA, Guillou PJ. Interleukin-10 release and monocyte human leukocyte antigen-DR expression during femoral nailing. Clin Orthop Relat Res. 2000;373:233-240.

38. Song SH, Sinha S, Kim TY, Park YE, Kim SJ, Song HR. Analysis of corticalization using the pixel value ratio for fixator removal in tibial lengthening. J Orthop Sci. 2011;16:177-183.

39. Sun XT, Easwar TR, Stephen M, Song SH, Kim SJ, Song HR. Comparative study of callus progression in limb lengthening with or without intramedullary nail with reference to the pixel value ratio and the Ru Li's classification. Arch Orthop Trauma Surg. 2011;131:1333-1340.

40. Thaller PH, Fürmetz J, Wolf F, Eilers T, Mutschler W. Limb lengthening with fully implantable magnetically actuated mechanical nails (PHENIX $®$ ): preliminary results. Injury. 2014;45(suppl 1):S60-65.

41. Utvåg SE, Grundnes $\mathrm{O}$, Reikerås $\mathrm{O}$. Graded exchange reaming and nailing of non-unions: strength and mineralisation in rat femoral bone. Arch Orthop Trauma Surg. 1998;118:1-6.

42. Wagner H. Surgical lengthening or shortening of the femur and tibia: technique and indications. In: Hungerford DS, ed. Leg Length Discrepancy. The Injured Knee. Berlin, Germany: Springer; 1977;71-94.

43. Watanabe K, Tsuchiya H, Sakurakichi K, Yamamoto N, Kabata T, Tomita K. Tibial lengthening over an intramedullary nail. $J$ Orthop Sci. 2005;10:480-485.

44. Yamasaki Y, Narita S, Toh S, Kashima I. Evaluation of lengthened callus by callotasis with analysis of mathematical morphology. J Orthop Sci. 2008;13:211-217.

45. Zhao L, Fan Q, Venkatesh KP, Park MS, Song HR. Objective guidelines for removing an external fixator after tibial lengthening using pixel value ratio: a pilot study. Clin Orthop Relat Res. 2009;467:3321-3326. 